\title{
Ginástica laboral do trabalhador no setor Administrativo de um órgão público na região metropolitana de Porto Alegre/RS
}

\author{
Labor gymnastics in the administrative sector in of a public \\ agency in the metropolitan region of Porto Alegre/RS
}

\author{
Cíntia Costa Medeiros Martins ${ }^{1}$
}

Agnes Ivana Koetz Aloisio ${ }^{1}$

RESUMO

Objetivo: Verificar os efeitos da Ginástica Laboral na presença de sintomas osteomusculares dos trabalhadores no setor administrativo de um órgão público na Região Metropolitana de Porto Alegre. Métodos: 0 estudo foi observacional, analítico e longitudinal, foi composto pela participação de 15 funcionários do setor administrativo com faixa etária de 24 a 60 anos, que trabalham no setor administrativo de um órgão público na Região Metropolitana de Porto Alegre. Foi aplicado o Diagrama de Corlett, ficha de identificação com os dados sócio demográficos no período de abril a junho de 2013. Resultados: Em relação à dor, os locais mais mencionados e com menor graduação na escala de dor ou desconforto de Corlett 11, forma tornozelos, pé esquerdo e perna direita. Com graduação maior foram perna direita e joelho esquerdo, antes do programa de ginástica laboral. Após o programa de ginástica laboral, a maioria da amostra referiu dor em menor local, em tornozelo esquerdo e nenhum integrante referiu dor grau máximo. Conclusão: É possível inferir que a fisioterapia em um programa de Ginástica Laboral traz benefícios, melhorando a qualidade de vida nos aspectos físicos e evitando distúrbios osteomusculares.

\section{PALAVRAS-CHAVE}

Ginástica Laboral; Fisioterapia; Saúde do trabalhador.

\footnotetext{
${ }^{1}$ Universidade Luterana do Brasil.
} 


\section{ABSTRACT}

Objective: To verify the effects of the Labor Gymnastics in the presence of osteomuscular symptoms of workers in the administrative sector of a public agency in the Metropolitan Region of Porto Alegre. Methods: The study was observational, analytical and longitudinal, it was composed by the participation of 15 employees from the administrative sector with ages ranging from 24 to 60 years old, that work in the administrative sector of a public agency in the Metropolitan Region of Porto Alegre. It was applied tThe Corlett Diagram, identification form with the socio-demographic in the period of April to June 2013. Results: In regard to pain, the most mentioned sites and with lower graduation in pain or discomfort scale of Corlett 11, forms ankles, left foot and right leg. With greater graduation were right leg and left knee, before the workout program. After the workout program the majority of the sample reported pain in minor local, left ankle and no member referred pain maximum degree. Conclusion: It is possible to infer that physical therapy in a Gymnastic Program provides benefits, improving the quality of life in the physical aspects and avoiding musculoskeletal disorders.

\section{KEYWORDS}

Labor Gymnastics; Physical Therapy; worker health. 


\section{INTRODUÇÃO}

A Ginástica Laboral (GL) é uma atividade desenvolvida como o intuito de prevenção de doenças laborais inclusas nos grupos LER (Lesões por Esforços Repetitivos) e DORT (Distúrbios Osteomusculares Relacionados ao Trabalho), sendo a mesma também denominada como ginástica na empresa, que visa a promoção da saúde, melhora das condições de trabalho e a preparação biopsicossocial do trabalhador LIMA, 2018; MARTINS, 2015).

A GL possibilita a diminuição de acidentes de trabalho e das doenças profissionais, proporciona ao trabalhador a quebra das ações rotineiras, prepara a musculatura para as práticas do ambiente de trabalho, ativa a circulação do sangue, aumenta a oxigenação cerebral e contribui para resgatar a atenção e a concentração nas atividades profissionais, tendo como finalidade a prevenção e a reabilitação das doenças ocupacionais (tendinites e distúrbios osteomusculares relacionado ao trabalho - DORTS), promovendo a saúde física e psíquica por meio de exercícios adequados e dirigidos para esse propósito(MESQUITA, 2012; MENDES, 2004; GONÇALVES,2018).

Nessa perspectiva, Lima e Nogueira (2017), ao citarem Martins e Barreto (2001), esclarecem que a GL pode ser classificada nos seguintes tipos: preparatória compensatória e de relaxamento, com sessões com a duração de 5, 10 ou 15 minutos, que tem como principais objetivos a prevenção das LER/DORT e a diminuição do estresse através dos exercícios resistidos e ativos, de alongamentos e de relaxamentos realizados no ambiente de trabalho.

A GL preparatória é uma série de exercícios para atividades de velocidade, força e resistência, que tem por objetivo a prevenção de acidentes, distensões musculares e doenças ocupacionais, bem como a melhoria das condições físicas e mentais, pois prepara os trabalhadores a enfrentarem aos estímulos, especialmente quando correm riscos de erros ou acidentes, ou a exigência de manipulação de maquinários e equipamentos os quais devem manter o seu foco e atenção para o uso de força ou intensa repetição de movimentos (GONÇALVES, 2018; LIMA, 2018).

Em relação à ginástica compensatória, a sua finalidade é realizar a compensação de estruturas osteomusculares que sofreram sobrecarregas devido a frequência de esforços efetuados, bem como favorecer posturas mais adequadas durante os períodos laborais contínuos. E, por fim, a ginástica de relaxamento é uma modalidade efetuada ao final das atividades e tem por objetivo atingir o relaxamento e descompressão das estruturas músculos e ligamentos durante a demanda das ocupações diárias. Tais exercícios de alongamentos, ao serem praticados no final da jornada de trabalho, melhoram a oxigenação dos músculos, evitando o acúmulo de resíduos metabólicos que afetam o organismo e causam danos à qualidade do sono do trabalhador, e que em curto prazo, acabam repercutindo na sua capacidade laboral (GONÇALVES, 2018; MAZZONETTO, 2016).

\section{SAÚDE DO TRABALHADOR}

Segundo Lima e Nogueira (2017), as primeiras iniciativas da implantação da GL no Brasil e em outros países ocorreram no setor de indústrias e hoje já abrangem os setores do comércio, prestação de serviços e serviço público, bem como universidades e escolas públicas e particulares.

No Brasil, as primeiras manifestações de atividades físicas entre funcionários foram em 1901, mas a GL teve sua proposta inicial publicada em 1973. Algumas empresas começaram a investir em empreendimentos com opção de lazer e esporte para os seus funcionários, como a Fábrica de Tecidos Bangu, a pioneira, e o Banco do Brasil, com a posterior criação da Associação Atlética do Banco do Brasil (LIMA, 2018).

A Saúde do Trabalhador (ST) é resultante de um patrimônio acumulado no âmbito da Saúde Coletiva (promoção, prevenção e vigilância). 0 avanço científico da Medicina Preventiva, da Medicina Social e da Saúde Pública, durante os anos 1960/70, ampliou o quadro interpretativo do processo saúde-doença vinculado ao trabalho. Essa nova forma de apreender a relação trabalho-saúde e de intervir no mundo do trabalho introduz, na Saúde Pública, práticas de atenção à saúde dos trabalhadores, com novas propostas da Reforma Sanitária Brasileira. Nessa perspectiva, a ST configura-se como sendo um campo de práticas e de conhecimentos estratégicos interdisciplinares (técnicos, sociais, políticos, humanos), multiprofissionais e interinstitucionais, voltados para analisar e intervir nas relações de trabalho que provocam doenças e agravos (LIMA,2018). 
Assim, no âmbito da ST no Brasil, o Ministério da Saúde ${ }^{1}$ instituiu a Política Nacional de Saúde do Trabalhador e da Trabalhadora, no ano de 2012, conforme a Portaria no 1823/12, que, entre outras finalidades, diretrizes e princípios do Sistema Único de Saúde (SUS), visa a promoção e a proteção da saúde dos trabalhadores, bem com a diminuição da morbidade e mortalidade ocorridas nos processos de produção, seja qual for a sua forma de inserção no mercado ocupacional trabalhista (MINISTÉRIOS DA SAÚDE, 2017).

A GL tendo sido desenvolvida e aplicada, com mais evidência, por profissionais da fisioterapia e educação física, no entanto ela também tem sido tocada por outras áreas, revelando ser um âmbito com tendência multiprofissional (LONGEN, 2003). Após a aprovação da implantação da GL nas empresas, as sessões devem ser conduzidas por um profissional da área da saúde, para que se faça um estudo adequado das atividades que serão propostas para os funcionários, e que se enquadre nas suas atividades do dia-a-dia. As séries devem ser montadas a partir da seleção de movimentos, observando-se as condições de trabalho, postura laboral, ambiente, equipamentos e uniforme. Devem ser de baixa intensidade de esforço, atingindo movimentos musculares antagônicos aos que se encontram em ação durante o trabalho, e proporcionando compensação e consequente reequilíbrio fisiológico (FARINATTI, 2016).

Mazzonetto e Teixeira-Arroyo (2016), ao mencionarem Zilli (2002), em seu estudo, salientam que a instauração de um programa de GL deve ser minuciosa e que o profissional deve considerar os aspectos psicológicos e motivacionais do trabalhador, além dos aspectos laborais e mecânicos. Para tanto, o processo de implantação da GL deve passar pelas seguintes etapas: pré-projeto; pré-implantação e implantação; consolidação; comprometimento; sustentação, contatos e negociação e avaliação.

Quando as empresas resolvem implantar um programa de GL, elas frequentemente constatam que são obtidos ganhos no ambiente de trabalho e que, assim, acabam por favorecer um melhor relacionamento das pessoas, pois além melhorar as condutas e posturas laborais, diminuem também os níveis de estresse do trabalhador. Em alguns casos, a GL consegue diminuir as faltas ao trabalho e contribuir com a qualidade de vida, tendo em vista que a satisfação e a motivação dos traba- lhadores estão frequentemente ligada ao comprometimento com o serviço e à produtividade da empresa (MADUREIRA, 2016).

De acordo com Laux et al. (2016), ao citarem uma pesquisa realizada por Candotti, Stroscheune Noll (2011), eles destacam que um grupo de trabalhadores que praticaram a GL, durante três meses, obtiveram como resultados uma considerável redução em suas dores musculares, sendo, portando, considerado um dos possíveis fatores para a diminuição de atestados médicos nos locais de trabalho (MADUREIRA, 2016).

Para Lima e Nogueira (2017), em visitas realizadas nos setores administrativos, bancos, prefeituras e órgãos públicos, verificou-se que os profissionais ligados à GL desenvolvem essas atividades buscando um efetivo desenvolvimento do programa implantado, buscando com isso aliviar o stress de uma carga diária de oito horas de trabalho dos servidores, tendo em vista o uso prolongado de computadores Contudo, essa prática deve ser realizada com o consentimento e de livre espontânea vontade do funcionário ou servidor público. Devendo que esclarecimentos sejam prestados a respeito dos benefícios da GL como sendo uma opção e não uma obrigação imposta pelo local de trabalho.

\section{DISTÚRBIOS OSTEOMUSCULARES OCUPACIONAIS}

Os distúrbios osteomusculares relacionados ao trabalho (DORT) correspondem a uma série de condições resultantes da inflamação ou degeneração de tendões, nervos, ligamentos, músculos e estruturas periarticulares em diferentes partes dos membros superiores do corpo humano, como por exemplo: dedos, punhos, antebraços e braços, ombros, região cervical e pescoço. Em função disso, os DORT's tornaram-se um problema de saúde que ocasiona encargos econômicos aos empregadores, trabalhadores e seguros de saúde (ASSUNÇÃO, 2017).

De acordo com os dados estatísticos do IBGE $(2015)^{17}, 5,5 \%$ das pessoas deixaram de realizar as suas atividades por motivo de DORT, num período de 2 semanas. 0 Brasil tem uma das taxas mais altas de doenças ocupacionais e acidentes de trabalho do que na América Latina, que são responsáveis por altos custos sociais e produtividade reduzida. Dados do governo brasileiro mostram que não só os DORT's são a primeira causa de 
doenças ocupacionais no país, mas também as notificações no sector industrial aumentaram progressivamente nos últimos anos (ASSUNÇÃO, 2017; IBGE, 2015).

Laux et al. (2016), também destacaram que as doenças físicas orteomusculares como por exemplo: LER/ DORT, se não forem devidamente prevenidas e tratadas, as doenças osteomusculares podendo ir muito além de aspectos físicos, podendo reverberar no psiquismo do trabalhador.

Nesse contexto, vale destacar que a ergonomia, ciência que estuda a relação entre o homem e a atividade que ele executa no local de trabalho, tem como objetivo integrar, de forma eficiente, as condições do ambiente de laborativo às capacidades e às limitações físicas e psicológicas do trabalhador (JACKSON FILHO, 2015).

Os pesquisadores Jackson Filho e Lima (2015), salientam que o desenvolvimento da ergonomia no Brasil está intrinsecamente conectado à resolução da epidemia brasileira de DORT ocorrida entre o final dos anos 80 e início dos anos 90, demonstrado que um aumento na consciência de ergonomia favorece à resolução de problemas nos locais de trabalho, o que pode levar a mudanças qualitativas mais amplas no trabalho. A ergonomia é considerada como uma das formas de melhorar as condições de rendimento dos trabalhadores, porém a conscientização da aplicação da ergonomia e seus benefícios ainda é baixa em muitos países desenvolvidos, inclusive no Brasil, tendo em vista que a aplicação dos princípios da ergonomia difere entre os países em desenvolvimento e países industrialmente avançados (JACKSON FILHO; MAENO, 2015).

\section{QUALIDADE DE VIDA NO TRABALHO}

Na busca da melhora da qualidade para a realização das atividades dos trabalhadores, a GL surgiu com o intuito de aumentar a atividade física saudável no trabalho. Ela foi desenvolvida com a intenção de oferecer melhores condições para a realização do trabalho, além de diminuir o nível de sedentarismo, tornando os funcionários mais dispostos, prevenindo acidentes, exercitando o corpo e tornando a relação com os colegas de trabalho mais produtiva e salutar. Vale destacar, ainda, que para alguns, o tempo destinado à prática de Ginástica Laboral é insuficiente para alteração de alguns desfechos de saúde (ALVAREZ, 2002). Somando-se aos ante- riores, outros autores acreditam que a GL pode potencialmente ser benéfica aos trabalhadores, possibilitando o desenvolvimento de comportamentos positivos também fora do ambiente empregatício (SESI, 2009; MINISTÉRIO DA SAÚDE, 2017; ALVAREZ, 2002).

De acordo com um estudo realizado por Dal Forno e Finger (2015), em que foi realizada uma revisão da visão de alguns autores sobre o assunto na perspectiva da qualidade de vida no trabalho, visto que a mesma está totalmente ligada a Ginástica Laboral. 0 referido estudo destaca que uma das origens do movimento de qualidade de vida do trabalho no Brasil teve início na década 50 , com o surgimento da abordagem sociotécnica. Eles esclarecem, também, que, nos anos de 1960, ocorreram iniciativas por meio de cientistas sociais, líderes sindicais, empresários e governantes, com o intuito de impulsionarem melhores formas de organizar o trabalho, visando atenuar os efeitos negativos das atividades laborais na saúde e bem-estar geral dos trabalhadores (DAL FORNO, FINGER, 2015).

Outrossim, Serafim et al. (2012), ao aludirem Schibuola (2005), em sua pesquisa, eles ressaltam a importância de um olhar mais atento das empresas e dos profissionais da área da saúde, no tocante aos fatores psicossociais que influenciam enormemente a adaptação laboral de seus funcionários, os quais podem ocasionar sintomas como: depressão, burnout, taquicardia, cefaléia tensional, enrijecimento muscular e distúrbios musculoesquelético, por exemplo. Além disso, um outro aspecto que merece ser destacado é o que se refere à fadiga física e mental, que está relacionada com a sensação de baixa vitalidade, sendo responsável pela diminuição da capacidade laborativa e que geralmente acomete os trabalhadores que desenvolvem as suas funções acompanhadas de sentimentos e emoções subjetivas como raiva e medo, por exemplo, cumulativamente com o excesso de responsabilidade pela segurança (pessoas e objetos), sendo também considerada como um fenômeno multidimensional (LIMA, 2017; FARINATTI, 2016).

Segundo Neves et al. (2018), uma contribuição da qualidade de vida do trabalho foi descrita com propriedade por Herzberg(1968), ao falar que: “...os indivíduos adquirem senso de auto realização e sucesso por meio do próprio trabalho - e não tão somente de fatores do ambiente - e ao associar a satisfação com o conteúdo do cargo ou trabalho (CACCIALORI et al., 2015). 
Além disso, os pesquisadores Marcon e Sturmer (2016), destacaram que outro fator que possivelmente pode explicar a diminuição dos atestados por doenças osteomusculares está evidenciado na pesquisa de Alves e Vale (1999), quando relataram a diminuição da intensidade e frequência das dores nos grupos musculares envolvidos no trabalho diário, após três meses de intervenção com a GL.

Nos dias de hoje, investir na qualidade de vida voltada aos funcionários nas empresas constitui uma das principais ações para a prevenção de problemas oriundos da prática e do ambiente laboral que, em condições inadequadas, podem ocasionar, pelo excessivo ritmo de trabalho, grandes males à saúde dos trabalhadores. Existem bons exemplos de instituições e empresas que têm como premissa proporcionar as melhores condições de trabalho a seus funcionários, mas grande parte ainda conduz os seus planejamentos tendo como base o que os trabalhadores podem produzir, e ainda não investem o suficiente para a promoção da qualidade de vida de seus colaboradores (SESI, 2009).

Os programas de promoção da saúde e melhoria da qualidade de trabalho, designadamente por meio da GL, deveriam integrar a cultura das empresas e órgãos públicos (ASSUNÇÃO, ABREU, 2917; DALFORNO, FINGER, 2015). Assim, em função do acima exposto, justifica-se a implantação do programa de GL para os servidores públicos administrativos da Prefeitura Municipal de Cachoeirinha/RS, que realizam seu trabalho de cunho burocrático, em sua imensa maioria, com uso de computadores, em posturas estáticas (NEVES et al., 2018).

\section{MÉTODOS}

0 presente estudo contou com uma amostra de 15 indivíduos de um órgão público da Região Metropolitana de Porto Alegre/RS, que participaram do programa de ginástica laboral, de ambos os sexos, sendo $10 \mathrm{mu}-$ lheres $(66,67 \%)$ e 5 homens $(33,33 \%)$, com média de 45,67 anos, sendo a mínima 24 e a máxima 60 anos. Todos os funcionários trabalhavam 8 horas por dia totalizando 40 horas por semana.

0 estudo foi observacional, analítico e longitudinal, com a participação voluntária de trabalhadores de um órgão público da Região Metropolitana de Porto Alegre/ RS, no período de abril a junho de 2013. Este trabalho atende aos preceitos éticos, sendo realizado após a aprovação do Comitê de Ética e Pesquisa (CEP) sobre o número do parecer: 15467813.3.0000.5349 da Universidade Luterana do Brasil - ULBRA.
Todos os participantes da pesquisa assinaram um Termo Livre e Esclarecido (TCLE), foi aplicado uma ficha de identificação contendo o nome, data da avaliação, escolaridade, sendo considerado o último ano completo cursado, sexo, estado civil, acesso de moradia, naturalidade, raça sendo esta autodeclarada, principal atividade profissional/ocupação exercida, ocupação atual, salário, números de pessoas com quem mora, uso de dispositivo assistido à marcha (SAMPAIO, OLIVEIRA, 2013). Os instrumentos utilizados para a coleta das informações foram compostos de uma ficha de identificação dos servidores para obtenção de informações sócias demográficas e econômicas, onde constavam com: caracterização demográfica da amostra investigada; descrição das variáveis: função, ocupação exercida, recursos financeiros, plano de saúde e acesso a moradia; descrição das variáveis relacionadas à saúde (SAMPAIO, OLIVEIRA, 2013).

Foi aplicado do Diagrama de Corlette Bishop (1976), antes e após o programa de Ginástica Laboral, que buscou identificar os sintomas musculoesqueléticos de acordo com o Diagrama de Corlett e Bishop (1976). 0 diagrama apresenta o corpo humano visto de costas, dividido em 24 segmentos, do lado direito e esquerdo, que é uma avaliação que consiste na ilustração do corpo humano dividido em 22 partes ou regiões dolorosas identificadas com nome e número, dispostas com uma graduação de dor a ser identificada pelo participante da avaliação. Assim sendo, nesta pesquisa, o Diagrama de Corlett (1976) avaliou o grau da dor da seguinte forma: 1 nenhum desconforto ou dor; 2 algum desconforto ou dor; 3 moderado; 4 bastante; 5 intolerável desconforto ou dor.

A GL era aplicada através do uso de protocolos criados pela autora do estudo, com base em estudos publicados sobre o tema. Os protocolos designados foram aplicados da seguinte maneira: 3 vezes por semana com duração de 15 minutos para cada grupo fechado. Estes protocolos foram divididos em semanas ímpares e pares. Nas segundas-feiras foram realizados alongamentos de membros superiores, tronco e membros inferiores, sendo os mesmos constituídos por duas séries de 20 segundos. Nas quartas-feiras, exercícios resistivos e ativos para membros superiores, tronco e membros inferiores E nas sextas-feiras foram utilizados relaxamentos, para membros superiores, tronco e membros inferiores.

Para o tratamento dos dados foi utilizada uma análise descritiva, através de percentuais e médias, dos dados sócios demográficos. As análises de dados obtidos pelo Diagrama de Corlett e pelo Questionário de 
Satisfação com a ginástica laboral foram realizadas por intermédio do Pacote Estatístico SPSS, versão 10.0, com nível de significância de $(p \leq 0,05)$ (CORLETT; BISHOP, 1976).

\section{RESULTADOS}

Quanto à escolaridade, a maioria dos participantes possuía ensino médio completo, representando um total de 13 participantes, seguido pelo ensino superior incompleto, com 2 (tabela 1). Vale ressaltar que todos os participantes, exercem funções de nível médio (tabela 2). Três funcionários da Junta Administrativa de Recurso de Infração (JARI) ocupavam o cargo de auxiliar administrativo, seis funcionários do setor de obras ocupavam o cargo de auxiliar administrativo, e seis da Secretaria Municipal de Transportes e Trânsito (SMTT) que ocupavam o cargo de setor administrativo, totalizando 15 funcionários.

Tabela 1. Caracterização demográfica da amostra investigada ( $\mathrm{n}=15)$.

\begin{tabular}{llcc}
\hline Variável & Categoria & No casos & $\%$ \\
\hline Idade & Menos de 50 anos & 7 & 46,7 \\
& 50 anos ou mais & 8 & 53,3 \\
\hline \multirow{2}{*}{ Sexo } & Feminino & 10 & 66,7 \\
& Masculino & 5 & 33,3 \\
\hline Raça & Branca & 13 & 86,7 \\
& Negra & 2 & 13,3 \\
\hline \multirow{2}{*}{ Estado Civil } & Casado & 66,7 \\
& Solteiro & 10 & 33,3 \\
\hline \multirow{2}{*}{ Escolaridade } & Colegial Completo & 5 & 20,0 \\
& Ginásio Completo & 3 & 40,0 \\
& Superior completo & 6 & 13,3 \\
& Superior Incompleto & 2 & 26,7 \\
\hline Arranjo de Moradia & Com Filhos & 4 & 6,7 \\
& Com Pais & 1 & 6,7 \\
& Cônjuge & 1 & 73,3 \\
& Tias & 11 & 6,7 \\
& Sozinha & 1 & 6,7 \\
\hline
\end{tabular}

Tabela 2. Descrição das variáveis: função, ocupação exercida, recursos financeiros, plano de saúde e acesso a moradia (n=15).

\begin{tabular}{llll}
\hline Variável & Categoria & № casos & $\%$ \\
\hline Função & Administrativo & 15 & 100,0 \\
\hline Ocupação Exercida & Cargo Técnico & 15 & 100,0 \\
\hline Recursos Financeiros & Salário & 15 & 100,0 \\
\hline Plano de Saúde & Não & 5 & 33,3 \\
& Sim & 10 & 66,7 \\
\hline Acesso a Moradia & Difícil & 3 & 20,0 \\
& Fácil & 12 & 80,0 \\
\hline
\end{tabular}


Em relação as variáveis relacionadas à saúde (tabela 3), os itens avaliados no que se refere a doenças e feridas.

Tabela 3. Descrição das variáveis relacionadas à saúde (n=15).

\begin{tabular}{llll}
\hline Variável & Categoria & № casos & $\%$ \\
\hline Doenças Crônicas e Feridas & Bursite & 1 & 6,7 \\
& Chagas, Varizes e Insônia & 1 & 6,7 \\
& HAS & 2 & 13,3 \\
& Insônia & 1 & 6,7 \\
& Osteoartrite, Depressão e Insônia & 1 & 6,7 \\
& Varizes & 5 & 33,3 \\
& Varizes e Insônia & 5 & 6,7 \\
& Nenhuma & 1 & 20,0 \\
\hline Uso de Dispositivos & Não & 3 & 100,0 \\
\hline Dor & Não & 15 & 60,0 \\
& Sim & 9 & 40,0 \\
\hline Percepção de Visão & Boa & 6 & 73,3 \\
& Excelente & 11 & 13,3 \\
& Ruim & 2 & 13,3 \\
\hline Percepção de Audição & Boa & 2 & 60,0 \\
& Excelente & 9 & 33,3 \\
& Ruim & 5 & 6,7 \\
\hline
\end{tabular}

Na tabela 4 estão descritas as variáveis relacionadas ao grau de dor se refere ao diagrama de Corlett antes do programa de ginástica laboral.

Na tabela 4, através dos resultados do teste não-paramétrico de Wilcoxon, verificou-se que não existe diferença significativa para os graus de dor do Diagrama de Corlett entre os períodos antes e após. Tendo como critério de exclusão da amostra durante o programa de ginástica laboral, 1 funcionária que se desligou da empresa por motivos de saúde.

Tabela 4. Grau de Dor - Diagrama de Corlett.

\begin{tabular}{|c|c|c|c|c|c|c|c|c|c|c|}
\hline \multirow{3}{*}{ Local } & \multicolumn{10}{|c|}{ Grau de Dor - Diagrama de Corlett } \\
\hline & \multicolumn{2}{|c|}{ Grau 1} & \multicolumn{2}{|c|}{ Grau 2} & \multicolumn{2}{|c|}{ Grau 3} & \multicolumn{2}{|c|}{ Grau 4} & \multicolumn{2}{|c|}{ Grau 5} \\
\hline & $\mathrm{N}$ & $\%$ & $\mathrm{n}$ & $\%$ & $\mathrm{n}$ & $\%$ & $\mathrm{n}$ & $\%$ & $\mathrm{n}$ & $\%$ \\
\hline \multicolumn{11}{|l|}{ Período Antes } \\
\hline Joelho Esquerdo & 10 & 66,7 & 2 & 13,3 & 1 & 6,7 & 1 & 6,7 & 1 & 6,7 \\
\hline Perna Direita & 7 & 46,7 & 3 & 20,0 & 2 & 13,3 & 1 & 6,7 & 2 & 13,3 \\
\hline Perna Esquerda & 10 & 66,7 & 2 & 13,3 & 1 & 6,7 & 1 & 6,7 & 1 & 6,7 \\
\hline Tornozelo Direito & 12 & 80,0 & 1 & 6,7 & - & - & 1 & 6,7 & 1 & 6,7 \\
\hline Tornozelo Esquerdo & 12 & 80,0 & 2 & 13,3 & - & - & 1 & 6,7 & - & - \\
\hline Pé Direito & 11 & 73,3 & 2 & 13,3 & 1 & 6,7 & 1 & 6,7 & - & - \\
\hline Pé Esquerdo & 12 & 80,0 & 1 & 6,7 & 1 & 6,7 & 1 & 6,7 & - & - \\
\hline
\end{tabular}

Período Após 


\begin{tabular}{|c|c|c|c|c|c|c|c|c|c|c|}
\hline Joelho Esquerdo & 10 & 71,4 & - & - & 2 & 14,3 & 2 & 14,3 & - & - \\
\hline Perna Direita & 10 & 71,4 & 1 & 7,1 & 3 & 21,4 & - & - & - & - \\
\hline Perna Esquerda & 10 & 71,4 & 2 & 14,3 & 1 & 7,1 & 1 & 7,1 & - & - \\
\hline Tornozelo Direito & 9 & 64,3 & 1 & 7,1 & 1 & 7,1 & 3 & 21,4 & - & - \\
\hline Tornozelo Esquerdo & 12 & 85,7 & - & - & 1 & 7,1 & 1 & 7,1 & - & - \\
\hline Pé Direito & 10 & 71,4 & 2 & 14,3 & 2 & 14,3 & - & - & - & - \\
\hline Pé Esquerdo & 9 & 64,3 & 3 & 21,4 & 2 & 14,3 & - & - & - & - \\
\hline Perna Esquerda & 10 & 71,4 & 2 & 14,3 & 1 & 7,1 & 1 & 7,1 & - & - \\
\hline Tornozelo Direito & 9 & 64,3 & 1 & 7,1 & 1 & 7,1 & 3 & 21,4 & - & - \\
\hline Tornozelo Esquerdo & 12 & 85,7 & - & - & 1 & 7,1 & 1 & 7,1 & - & - \\
\hline Pé Direito & 10 & 71,4 & 2 & 14,3 & 2 & 14,3 & - & - & - & - \\
\hline Pé Esquerdo & 9 & 64,3 & 3 & 21,4 & 2 & 14,3 & - & - & - & - \\
\hline
\end{tabular}

\section{DISCUSSÃo}

Camargo e Bueno (2012), ao citarem Pisters (2007), salientam a importância da adesão dos trabalhadores aos programas da melhoria de qualidade de vida no trabalho, neles incluída a prática da GL, podendo ser aplicados cada vez mais nas empresas de pequeno, médio e grande porte. Sabe-se que no Brasil as atividades inerentes aos profissionais de nível não superior ainda são as que exigem uma maior sobrecarga em maior número de horas em relação ao nível superior. Sendo assim, percebe-se que desse grupo a maior parte dos funcionários está sujeita aos riscos decorrentes de maiores doenças osteomusculares, para a realização de suas atividades de trabalho (IZAIAS, 2015).

Já Teixeira e Delatorri (2018), em seu estudo relataram que os benefícios gerados pela GL consistem em prevenção de dores, aumento da disposição e flexibilidade e relacionamento interpessoal. A GL pode ser vista como uma dinâmica de vida saudável para os trabalhadores. No estudo dos autores observaram que muitas empresas já estão aderindo à prática e criando projetos de GL com o objetivo de proporcionar aos funcionários momentos de relaxamento, de cuidado com área física e emocional, e ao mesmo tempo, contribuindo para o crescimento da empresa, ou seja, investe no recurso humano com um olhar para um futuro financeiro bem melhor.

A baixa escolaridade dos trabalhadores é um fator que faz aumentar o número de horas trabalhadas, tornando os trabalhos excessivos e ocasionando posturas inadequadas. Além disso, os esforços excessivos, as repetições constantes de movimentos e as condições críticas de materiais, equipamentos e instalações nas empresas, contribuem para o desenvolvimento das tensões corporais. E estas, por sua veze, ocasionam os malefícios que são responsáveis pelo surgimento de doenças, podendo provocar ausências temporárias e até permanentes nos setores de trabalho (CAMARGO; BUENO, 2012; IZAIAS, 2015).

No estudo de Goulart (2016), o trabalho, por ser um dos alicerces principais da vida humana e da vida em sociedade, deve ser encarado de forma mais respeitosa. Apesar de percebermos que os estudos em psicodinâmica do trabalho já estão bem avançados para uma área que foi criada há menos de meio século, ainda há muito a que se expandir no Brasil e no mundo. Ocorre que as insatisfações no trabalho não são devidamente valorizadas por gestores, principalmente na esfera pública. 0 serviço público, por ser uma área que demonstra uma maior estabilidade e melhores salários, muitas vezes solicita da subjetividade do sujeito que supere e aguente situações precárias de organização do trabalho, que com o passar do tempo se torna demasiadamente imprópria para a saúde física e, principalmente, psíquica do indivíduo

As atividades no trabalho que causam uma sobrecarga, sejam elas mentais ou físicas, devem ser reconsideradas quanto a sua forma de compensação. Na maioria dos casos a adoção de pausas ameniza o problema, principalmente em um uso abusivo de movimentos re- 
petidos no dia-a-dia, seja a ocupação qual for exercida pelo funcionário, podendo ocasionar problemas no futuro. Uma recomendação a ser analisada é quanto à realização de pausas para descanso após a realização de atividades torna-se importante para recuperação da capacidade funcional, principalmente após os períodos ininterruptos (CAMARGO; BUENO, 2012; IZAIAS, 2015).

Segundo Santos et al. (2007) e Barbosa et al. (2014), a sobrecarga imposta por posturas inadequadas durante a jornada de trabalho como, por exemplo, trabalhar sentado com uma postura errada, afeta de forma gradativa todos os seguimentos corporais, levando o surgimento de dores, formigamentos e sensações de peso nas diversas estruturas corporais como punho, cervical, lombar e membros inferiores. Verificando que a repetição dos movimentos consiste em um fator de risco para o surgimento das doenças ocupacionais. Assim, o programa de Ginástica Laboral tem um papel fundamental nas empresas prevenindo distúrbios osteomusculares e evitando a sobrecarga de trabalho e o surgimento das doenças ocupacionais.

Santos et al. (2007) realizou um estudo com 40 funcionários da Universidade Paranaense da cidade de Umuarama (UNIPAR) e puderam verificar que antes da GL os trabalhadores apresentavam dores na região do pescoço (50\%) e após a aplicação da GL as dores diminuíram (47\%), observaram uma diminuição de (3\%). Neste estudo, a presença de algia em ombro, foi verificada em 3 pessoas $(33,33 \%)$ antes da Ginástica Laboral e após a aplicação da Ginástica Laboral 3 pessoas $(33,33 \%)$ apresentavam queixa de dor. Verificando que não houve melhora neste seguimento.

Segundo Lima e Nogueira (2017) e Medeiros et al. 2014), a realização dos exercícios do programa de Ginástica Laboral são benéficos, pois proporcionam um aumento na disposição e no ânimo para o trabalho, melhora da qualidade de vida e proporciona uma diminuição das dores e do cansaço no ambiente de trabalho.

Nessa perspectiva, em um estudo realizado por Moretto et al. (2017), com 48 costureiras de uma fábrica de confecções calça (jeans) na cidade de Londrina-PR, observou que 14 pessoas $(29,16 \%)$ apresentavam dor, antes da ginástica laboral e após a aplicação da ginástica laboral 9 pessoas 18,75\% apresentaram dor neste seguimento. Obtendo uma melhora de 10,41\%. A região do pescoço antes da ginástica laboral foi apresentada por 3 pessoas $(33,33 \%)$ e após aplicação da ginástica laboral 2 pessoas $22,22 \%$, relataram dores neste seguimento observando uma melhora de 11,11\%. 0 mesmo trabalho apresentado por pelo autor ${ }^{34}$, relata que antes da ginástica laboral 24 pessoas (50\%), sentia dores na região do pescoço e após a aplicação da ginástica laboral 16 pessoas $33,33 \%$ queixa de dor neste seguimento observando uma melhora de $16,67 \%$

De acordo com Martins, Nicolau, Cury-Boaventura (2015), torna-se importante investigar as lesões provenientes do trabalho e os benefícios da implantação da GL em um grupo de trabalhadores para poder verificar uma considerável diminuição dos índices nas parestesias e dormência dos membros superiores, bem como uma melhora da flexibilidade da cervical e do tronco dos participantes, após seis meses de implantação do programa. Aspectos estes que contribuem para a redução de queixas osteomusculares nas regiões corporais mais frequentemente prejudicadas por suas atividades profissionais.

Para tanto, Mazzonetto e Teixeira (2016), esclarecem que a GL não deve ser compreendida somente como um exercício físico, mas, sim, como uma oportunidade para a reeducação de hábitos de vida dos funcionários que contribui para aumentar a capacidade para atividades laborais e ainda manter suficientes reservas de energia para enfrentar a rotina do dia-a-dia

Segundo Teixeira e Delatorri (2018), em seu estudo relataram que o desenvolvimento da GL contribui para a promoção da saúde e qualidade de vida dos trabalhadores abarcando não somente o nível individual, mas, social, econômico e psicológico. A GL contribui para diminuição dos gastos com médico e sem sombra de dúvida nos afastamentos do trabalho.

\section{CONCLUSÃO}

Assim, podemos concluir que a fisioterapia em um programa de GL traz benefícios, melhorando a qualidade de vida nos aspectos físicos e evitando distúrbios osteomusculares. Portanto, a aplicação do programa de Ginástica Laboral do setor administrativo mostrou que esta medida colocada em prática poderia ter sido aplicada por um tempo maior para obtenção de resultados significativos. Contudo foi observada a obtenção de um grau de satisfação elevado, entre os participantes da amostra. 
Os resultados da pesquisa foram possíveis traçar um caminho a seguir em trabalhos futuros. Os conjuntos dos resultados obtidos apontam para a necessidade de mais estudos sobre a psicodinâmica do trabalho dentro de órgãos públicos, principalmente com profissionais administrativos. Alguns conceitos que apareceram na pesquisa, como relação a saúde a função, ocupação exercida, recursos financeiros, plano de saúde e acesso a moradia, e a relação da dor possuem aspectos importantes no que diz respeito a atual realidade dos trabalhadores da individualidade e do excesso de trabalho, doenças pregressas, no entanto, não foi possível obter dados concretos sobre sua influência no sofrimento do indivíduo.
O presente estudo destaca a importância do programa de Ginástica Laboral como um meio de prevenção, uma ferramenta que auxilia os usuários a evitar o ocasionamento de distúrbios osteomusculares e futuras patologias por excesso de trabalho repetitivo. Diante do acima exposto, considera-se que a GL pode desenvolver um papel relevante ao ser incluída em programas de gestão de saúde e qualidade de vida nos ambientes de trabalho. Para tanto, sugere-se que novas pesquisas sejam realizadas sobre os aspectos significativos da implantação de um programa de GL na rotina trabalhista do servidor público. 


\section{REFERÊNCIAS}

ALVAREZ, B.R. Estilo de vida e hábitos de lazer de trabalhadores, após dois anos de aplicação de um programa de GL e saúde caso - Intelbras. Tese Doutorado - Programa de Pós-Graduação em Engenharia de Produção. Universidade Federal de Santa Catarina, 2002.

ASSUNÇÃO, A. A., ABREU, M. N. S. Fatores associados a distúrbios osteomusculares relacionados ao trabalho auto referidos em adultos brasileiros. Rev. Saúde Pública, v. 51, p. 1-10, 2017.

BARBOSA, Paulo Henrique; CARNEIRO, , Flavia; DELBIM, Lucas Risseti; HUNGER, Marcelo Studart; MARTELLI, Anderson. Doenças osteomusculares relacionadas ao trabalho e à ginástica laboral como estratégia de enfrentamento. Arch Health Invest, v. 3 n. 5, p. 57-65, 2014.

BRASIL. Ministério da Saúde. Boletim Epidemiológico Secretaria de Vigilância em Saúde v. 48, n. 18, 2017.

BRASIL. Ministério da Saúde. Portaria no 1.823, 23 de agosto de 2012. Política nacional da saúde do trabalhador. Brasília, DF, 2012.

BRASIL. Ministério do Planejamento. Pesquisa Nacional de Saúde: 2013. Orçamento e Gestão,Insstituto Brasileiro de Geografia e Estatística - IBGE. Rio de Janeiro: IBGE, 2015.

CACCIATORI, Fernanda; LIBERALI, Rafaela; ORNELLAS, Fabio Henrique; NAVARRO, Francisco. A influência da participação nas aulas de ginástica laboral na ocorrência de sinais e sintomas de infecções respiratórias. Revista Brasileira de Prescrição e Fisiologia do Exercício, São Paulo. v. 9. n.5 4. p. 410-419. Jul./Ago. 2015.

CAMARGO, Rosângela A. A. de; BUENO, Sônia M. Villela. Lazer, a vida além do trabalho para uma equipe de futebol entre trabalhadores de hospital. Rev. Latino-Am. Enfermagem [online]. 2003, v. 11, n. 4, p. 490-498. ISSN 1518-8345. http://dx. doi.org/10.1590/S0104-11692003000400012.

CORLETT, E. N.; BISHOP, R. P. A technique for measuring postural disconfort. Ergonomics, v. 19, n. 2, p. 175-82, mar. 1976.

DAL FORNO, CRISTIANO; FINGER, IGOR R. Qualidade de vida no trabalho: conceito, histórico e relevância para a gestão de pessoas. R. bras. Qual. Vida, Ponta Grossa, v. 7, n. 2, p. 103-112, abr./jun. 2015.

FARINATTI, P. T.; FERREIRA, M. S. Saúde, promoção da saúde e Educação Física: conceitos e aplicações. Rio de Janeiro: EDUERJ, 2016.

GOMEZ, C. M.; VASCONCELLOS, C. F.; MACHADO, J. M. H. Saúde do trabalhador: aspectos históricos, avanços e desafios no Sistema Único de Saúde. Ciênc. Saúde Coletiva, v. 6, n. 2, p. 1963-70, 2018.
GONCALVES, A. A. Ginástica Laboral como Ferramenta da Ergonomia. 2018.[ver.] mar. 201. Disponível em: http://alessandrogoncalves.com.br/ergonomia-do-trabalho-cursos-sobre-ler-e-dort/a-ginastica-laboral-como-ferramenta-da-ergonomia.

GOULART, Natália Lelis Gimarães. Trabalho em instituições públicas e sofrimento psíquico na contemporaneidade: uma revisão do estado da arte na plataforma scielo no período 2004-2013. Dissertação de Mestrado- Programa de Pós Graduação em Gestão de Políticas Públicas. Universidade Federal do Tocantins - UFT, 2016

IZAÍAS, Otaviana R.O. A implicação da prática de ginástica laboral na percepção de dor de funcionários de tele atendimento: uma revisão bibliográfica. Lume Repositório Digital. Universidade Federal do Rio Grande do Sul, Escola de Educação Física. 2015. Disponível em: https://lume.ufrgs.br/handle/10183/126463.

JACKSON FILHO, J.M.; MAENO, M. Desenvolvimentos da Análise Ergonômica do Trabalho no Brasil no contexto da desorganização do trabalho (Developments of Ergonomic Work Analysis in Brazil in the context of 'disorganization of work). Rev. bras. saúde ocup. v. 40, n. 131 São Paulo, jan./jun. 2015

LAUX, R. C., PAGLIARI, P.; EFFTING JUNIOR, J. V.; CORAZZA, S.T Programa de Ginástica Laboral e a Redução de Atestados Médicos. Ciencia \& Trabajo, v. 18, n. 56, 2016.

LIMA, F. V. B.; NOGUEIRA, R. J. C. C. A efetividade do programa de ginástica laboral. Revista de Administração de Roraima-UFRR; v.7, n. 2, p. 297-309, 2017.

LIMA, Valquiria de. Ginástica laboral:atividade física no ambiente de trabalho. 2 ed. São Paulo: Phorte, 2018.

LONGEN. Ginástica laboral na prevenção de LER/ DORT Um estudo reflexivo em uma linha de produção. [Dissertação -Mestrado]. Programa de pós-graduação em Engenharia de Produção Florianópolis (SC): Universidade Federal de Santa Catarina; 2003.

MADUREIRA, J. C. Análise de sintomas álgicos musculoesqueléticos e fadiga em acadêmicos estagiários de uma clínica escola de fisioterapia. Universidade Estadual da Paraíba, Centro de Ciências Biológicas da Saúde, Departamento de Fisioterapia. Campo Grande-PB: UEPB, 2016.

MARCON, Daniela Dicke; STURMER, Giovani. Labor gymnastics and the benefits for the worker Health: a narrative review. Revista Interdisciplinar de Ensino, Pesquisa e Extensão, v. 4, n. 1, p. 113-120, 2016

MARTINS, Patrícia F. de Oliveira; ZICOLAU, Evelin A. A.; CURY-BOAVENTURA, Maria F. Stretch breaks in the work setting improve flexibility and grip strength and reduce musculoskeletal 
complaints. Rio Claro, Motriz: rev. educ. fis. v. 21, n. 3, jul. set., 2015.

MAZZONETTO, L.F.; TEIXEIRA, C. Arroyo Adequacy of a workplace exercise program to the needs of workers from different sectors of a car dealership. Revista Hispeci\& Lema,; v. 7, n. 1 , p. 61-80, 2016.

MEDEIROS, Maira Lima; NOGUEIRA, Mariane Santos, VILLAR, Acácia de Castro. Benefícios da aplicação de um programa de ginástica laboral à saúde de trabalhadores. Rev. Eletrônica, Montes Belos, v 7, n. 1, 2014.

MENDES R. A.; LEITE, N. Ginástica laboral: princípios e aplicações práticas. Barueri: Manole, 2004.

MESQUITA, C. C.; RIBEIRO, J. C., MOREIRA P. Effect of a specific exercise program on the strength and resistance levels of lumbar muscles in warehouse workers. International Journal of Occupational Medicine and Environmental Health, v. 25, p. 80-88, 2012.

MORETTO, Anacléia Fernanda; CHESANI, Fabíola Hermes; GRILLO, Luciane Peter. Musculoskeletal disorder and quality of life in seamstresses in the city of Indaial, Santa Catarina, Brazil. Fisioterapia e Pesquisa, v. 2, n. 24, p. 163-168, 2017. Disponível em http://www.scielo.br/pdf/fp/v24n2/en_2316-9117fp-24-02-00163.pdf.
NEVES, R. F. N.; ARAÚJO, S. P. A.; MAGALHÃES, L. V.; LIMA, M. A. G. Ginástica laboral no Brasil entre os anos de 2006 e 2016: uma scoping review. RevBrasMed Trab., v. 16, n.1, p. 82-96, 2018.

SAMPAIO, Adelar Aparecido; OLIVEIRA, João Ricardo G. de. Promoção da saúde e melhoria da qualidade de vida no trabalho. Caderno de Educação Física. Marechal Cândido Rondon, v. 7, n. 13, p. 71-79, 2. sem. 2008.

SANTOS, Andréia Fuentes dos; ODA, Juliano Yasuo; NUNES, Ana Paula Mori, GONÇALVES, Luciano, GARNÉS, SANTOS, Fabrícia Lorca dos. Benefícios da ginástica laboral na prevenção dos distúrbios da ginástica laboral na prevenção dos distúrbios osteomusculares relacionados ao trabalho. Arq. Ciênc. Saúde Unipar, v. 11, n. 2, p. 99-113, 2007

SERAFIM, Alessandra da Cruz; CAMPOS, Izabel Carolina Martins; CRUZ, Roberto Moraes; RABUSKE, Michelli Moroni. Riscos psicossociais e incapacidade do servidor público: um estudo de caso. Psicol. cienc. prof. [online], vol. 32, n. 3, p. 686-705, 2012.

SESI. Estilo de vida e hábitos de lazer dos trabalhadores das indústrias brasileiras: relatório geral. Brasília, 2009. TEIXEIRA, Leonardo Moreira; DELATORRI, Maycon da Silva. Os impactos da atividade ginástica laboral (gl) no desempenho do trabalhador. Revista Dimensão Acadêmica, v.3, n.1, 2018. 